\title{
Oral traditions of the Kerinci community: proverbs, sayings, and old rules
}

\section{Tradisi lisan Masyarakat Kerinci: amsal, ungkapan, dan aturan lama}

\author{
Asvic Helida ${ }^{*}$, Ervizal Amir Muhammad Zuhud² \\ 1 Universitas Muhammadiyah Palembang, Indonesia. \\ ${ }^{2}$ Institute Pertanian Bogor (IPB), Indonesia. \\ *Correspondence author: asvic_helida@um-palembang.ac.id
}

\begin{tabular}{|c|c|}
\hline ARTICLE INFO & ABSTRACT \\
\hline $\begin{array}{l}\text { Keywords: } \\
\text { Traditional; Ecological } \\
\text { Knowledge; Oral } \\
\text { Tradition; proverb; old } \\
\text { sayings; Local } \\
\text { Community. } \\
\text { How to cite: } \\
\text { Helida, A., Zuhud, E.A.M. } \\
\text { (2021). Oral traditions of } \\
\text { the Kerinci community: } \\
\text { proverbs, sayings, and old } \\
\text { rules. Etnosia: Jurnal } \\
\text { Etnografi Indonesia, 6(1), } \\
\text { 66 - 81. } \\
\\
\text { DOI: } \\
\text { 10.31947/etnosia.v6i1.12455 }\end{array}$ & $\begin{array}{l}\text { Proverb of a community can indicate their level of knowledge on } \\
\text { natural resource and forest management. These expressions are an } \\
\text { effective way to learn about traditional ecological knowledge (TEK). } \\
\text { Differences or similarities in the knowledge systems of various ethnic } \\
\text { groups can be found by comparing their expressions. This traditional } \\
\text { ecological knowledge is passed down from generation to generation } \\
\text { through oral tradition. Oral traditions are not always reliable because } \\
\text { they depend on memory and oral transmission. However, unlike } \\
\text { proverbs, old sayings and societal rules have more validity by their } \\
\text { nature. Proverbs and old sayings are expressions of fundamental } \\
\text { truths or practical perceptions based on common sense or cultural } \\
\text { experience. The Kerinci community in Kerinci Regency, Jambi } \\
\text { Province, is known to have these expressions, but it has not been } \\
\text { documented. Therefore the significance of this research needs to be } \\
\text { done. The maintenance of expressions of oral tradition is a task from } \\
\text { generation to generation simultaneously so that the collection of } \\
\text { expressions in the form of proverbs, proverbs, and local rules from a } \\
\text { community group becomes essential for the development of science. } \\
\text { This study aims to document and analyze the expressions of the people } \\
\text { of Kerinci. The research method was carried out qualitatively with } \\
\text { library research techniques and interviews with resource persons. The } \\
\text { results show that there are } 30 \text { expressions of the Kerinci community } \\
\text { consisting of proverbs and old rules. These expressions show that the } \\
\text { people of Kerinci have the knowledge they get from nature and the } \\
\text { ecosystem in which they live. }\end{array}$ \\
\hline
\end{tabular}

1. Pendahuluan

Indonesia adalah negara megacultural, memiliki lebih dari 550 suku yang tersebar dari Sabang hingga Merauke. Mereka tersebar di lebih 73.798 desa (350.000 dusun atau 
kampung) yang telah hidup dan berinteraksi dengan lingkungan hutan di sekitar mereka (Helida, 2016). Setiap kelompok masyarakat memiliki tingkat pengetahuan yang berbeda dengan kelompok masyarakat suku lainnya. Selain karena perbedaan kondisi lingkungan, pengetahuan mereka juga dipengaruhi oleh tingkat kemajuan kebudayaan mereka. Tingkat pengetahuan yang dicapai oleh suatu kelompok masyarakat berasal dari adanya akumulasi dalam berinteraksi dengan alam lingkungan dimana mereka tinggal.

Berbagai kelompok masyarakat ini hidup pada berbagai tipe lingkungan seperti di daerah pegunungan, daerah sekitar hutan, di sepanjang sungai dan di daerah pesisir. Mereka hidup dan melakukan proses ko-eksistensi dengan alam sekitarnya. Berbagai kelompok masyarakat ini telah berinteraksi dengan alam, mereka mengamati dan belajar dengan cermat, bagaimana mengelola sumber daya dan melakukan proses adaptasi terhadap perubahan yang terjadi seperti gangguan iklim. Pengetahuan ini telah diturunkan dari generasi ke generasi yang secara umum disebut Pengetahuan Ekologi Tradisional (Traditional Ecological Knowledge).

Pengetahuan ekologi tradisional adalah akumulatif pengetahuan, praktik dan keyakinan dari satu kelompok masyarakat tentang hubungan makhluk hidup (termasuk manusia), satu sama lain dan dengan lingkungan mereka. Pengetahuan ini berkembang dengan proses adaptif melalui transmisi budaya secara turun temurun. Pengetahuan ekologi tradisional berguna untuk menganalisis semua aspek pengetahuan masyarakat tradisional tentang lingkungannya meliputi persepsi dan konsepsi mereka terhadap lingkungan dan sumber daya alam yang ada di dalamnya, menganalisis pengaruh formatif persepsi lokal tentang lingkungan dan pembangunan pengetahuan tersebut (Anderson, 2011).

Beberapa kajian menunjukkan bahwa pengetahuan ekologi tradisional ini dapat berperan dalam menjaga kelestarian lingkungan. (Helida, 2016) menyebutkan bahwa tradisi pelak, semacam sistem agroforestry yang dimiliki masyarakat Kerinci dapat menjaga kelestarian hutan dan sekaligus meningkatkan kesejahteraan hidup masyarakat Kerinci. Zhang et. al. (2016) juga menyebutkan bahwa tradisi hakka yang dimiliki oleh masyarakat lokal Cina telah memberikan kontribusi dalam proses restorasi kawasan hutan mereka. Galacgac \& Balisacan (2009), juga menyatakan bahwa peramalan tentang cuaca pada masyarakat lokal di Ilocos Norte Filipina telah memberikan keberhasilan dalam kegiatan agroforestry mereka.

Hasil ini membuktikan bahwa masyarakat tradisional memiliki pengetahuan yang baik terhadap pengelolaan lingkungan mereka. Hal ini diperkuat dalam United Nation (2014) yang menyatakan bahwa masyarakat dapat memberikan kontribusi pengetahuan tradisional mereka dalam pemanfaatan lingkungan secara efektif dan lestari. Pernyataan ini menunjukkan bahwa pengetahuan yang dimiliki oleh masyarakat dapat menginspirasi dunia dalam menghadapi perubahan serta mengurangi resiko bencana yang diakibatkannya.

Pengetahuan ekologi tradisional ini diturunkan dari generasi ke generasi melalui tradisi lisan yang proses penyampaiannya berupa pesan lewat perkataan dari mulut ke mulut selama beberapa waktu sampai pesan tersebut menghilang. Maka dari itu setiap tradisi 
lisan adalah sebuah versi pada satu masa, sebuah elemen dalam suatu proses pengembangan lisan yang dimulai oleh generasi tua suatu masyarakat lokal (Vansina, 1985). Mason (2020), menyatakan bahwa tradisi lisan tidak selalu dapat dipercaya karena tergantung pada daya ingat dan transmisi verbal. Namun berbeda dengan peribahasa, pepatah lama dan aturan masyarakat lebih memiliki validitas berdasarkan sifatnya. Peribahasa dan pepatah lama adalah ekspresi dari kebenaran dasar atau persepsi praktis yang berdasarkan akal sehat atau pengalaman budaya.

Peribahasa, pepatah lama ataupun aturan-aturan dari suatu masyarakat tradisional merupakan salah satu cara yang efektif untuk belajar tentang pengetahuan ekologi tradisional. Perbedaan atau kesamaan dalam sistem pengetahuan pada suatu masyarakat dapat ditemukan dengan membandingkan peribahasa, pepatah lama dan aturan-aturan komunitas yang mereka miliki. Sebagai contoh, dua kelompok etnis dengan lingkungan geografis yang sama mungkin memiliki cara yang berbeda untuk mengelola lingkungan hidup, atau cara yang sama tetapi dinyatakan secara berbeda. Pemahaman yang lebih baik dari peribahasa, pepatah lama dan aturan masyarakat dapat berkontribusi untuk memecahkan masalah-masalah masyarakat modern.

Oleh karena itu kajian tentang peribahasa, pepatah lama dan aturan-aturan yang dimiliki oleh satu masyarakat menjadi penting dilakukan guna mengungkap pengetahuan-pengetahuan mereka tentang sumber daya alam dan lingkungannya. Namun secara umum, baru sedikit penelitian yang mengungkapkannya, sehingga kajian ini memiliki signifikansi dalam pengumpulan dan memahami peribahasa, pepatah lama dan aturan-aturan masyarakat sebagai sarana mendokumentasikan pengetahuan ekologi tradisional.

Masyarakat tradisional pada umumnya memiliki filosofi hidup berorientasi kepada alam yang tercermin dalam ungkapan alam terkembang jadi guru. Bagi mereka, alam adalah sumber pengetahuan yang harus mereka pelajari sebagai suatu sistem nilai yang diyakini kebenarannya. Filsafat alam yang mereka anut tercermin dari ungkapanungkapan peribahasa, pepatah dan idiom-idiom. Oleh karena itu yang menjadi tujuan dari artikel ini adalah mendokumentasikan ungkapan-ungkapan lama, amsal dan aturan-aturan lokal masyarakat Kerinci serta menganalisis makna ungkapan-ungkapan tersebut dalam kaitannya sebagai suatu sumber ilmu pengetahuan dan manfaat dalam jasa lingkungan.

\section{Metode}

Penelitian dilakukan pada masyarakat suku Kerinci di Dusun Baru Lempur Kecamatan Gunung Raya Kabupaten Kerinci Provinsi Jambi. Data terdiri dari ungkapan-ungkapan bahasa asli dalam bentuk peribahasa, pepatah lama dan idiom-idiom yang biasa diucapkan oleh masyarakat Kerinci yang berhubungan dengan alam semesta. Metode pengumpulan data bersifat kualitatif dengan teknik studi pustaka dan wawancara. Irawan (2006) dan Neuman (2006) menyebutkan bahwa studi pustaka adalah segala usaha yang dilakukan oleh peneliti untuk menghimpun informasi yang relevan dengan topik atau masalah yang akan atau sedang diteliti. Informasi itu dapat diperoleh dari buku-buku ilmiah, artikel jurnal, laporan penelitian, karangan-karangan ilmiah, tesis dan disertasi, peraturan-peraturan, ketetapan-ketetapan, buku tahunan, ensiklopedia 
dan sumber-sumber tertulis baik tercetak maupun elektronik lain. Sedangkan wawancara adalah tanya jawab antara dua pihak yaitu pewawancara dan narasumber untuk memperoleh data, keterangan atau pendapat tentang suatu hal. Bentuk wawancara antara lain adalah wawancara bebas (open ended), wawancara berfokus, wawancara mendalam (depth interview) dan Focus Group Discuss (FGD).

Dalam penelitian ini, metode wawancara yang dilakukan adalah bersifat depth interview. Wawancara dilakukan kepada informan kunci atau narasumber yang ditunjuk. Penetapan informan kunci yang tepat didasarkan atas rekomendasi dari tokoh adat/tokoh masyarakat setempat (snowballing) yaitu dengan teknik penentuan informan berdasarkan petunjuk atau penentuan informan awal terhadap seseorang yang dianggap lebih mampu memberikan informasi sesuai kebutuhan penelitian. Dalam penelitian ini informan kunci terdiri dari 2 orang yang merupakan pemimpin masyarakat adat Dusun Baru Lempur. Kegiatan penelitian ini mengikuti langkahlangkah sebagai berikut:

a. Mengumpulkan peribahasa, pepatah tua dan aturan komunitas masyarakat Kerinci. Wawancara dilakukan untuk mengumpulkan peribahasa, pepatah dan aturan komunitas masyarakat Dusun Baru Lempur.

b. Mendokumentasikan peribahasa, pepatah tua dan aturan masyarakat dalam bahasa asli, dan diterjemahkan ke dalam bahasa resmi Bahasa Indonesia.

c. Mencatat kata kunci dari setiap ungkapan yang disampaikan.

d. Mengkategorikan ungkapan masyarakat ke dalam jasa ekosistem yang ada.

e. Seluruh ungkapan yang sudah dikumpulkan kemudian disajikan dalam bentuk tabulasi data untuk menjawab sesuai dengan tujuan penelitian.

\section{Hasil Penelitian}

\section{- Profil Masyarakat Kerinci}

Suku Kerinci di Provinsi Jambi merupakan salah satu suku tertua yang ada di Pulau Sumatera. Mereka telah ada sejak zaman megalithikum yang ditandai dengan penemuan alat-alat yang terbuat dari obsidian di pinggir Danau Kerinci, yang sama dengan alat-alat yang terdapat di Bandung, Jawa Barat yang merupakan inti dari kebudayaan megalithikum (Zakaria, 2012).

Hal yang sama juga dinyatakan dalam Kahar (1981), bahwa suku Kerinci merupakan bagian dari suku Melayu Tua. Pendapat ini secara kasat mata dapat dilihat dari (1) tipe orang Kerinci saat ini yang memperlihatkan banyak persamaan dengan Melayu Tua yang mirip dengan tipe Mongolid, mata sipit seperti kebanyakan mata orang Cina dan (2) bahasa Kerinci termasuk golongan bahasa Austronesia Barat yaitu bahasa Melayu Tua. Pernyataan ini menunjukkan bahwa suku Kerinci merupakan suku Melayu Tua yang sejajar dan sama tua dengan suku Bontog dan suku Igorot di Filipina, suku Tayal di Thailand, suku Kren di Pegunungan Birma dan Thailand, suku Wajo di Kepulauan Lingga Cebu, Filipina, suku Toraja di Sulawesi dan suku Batak di Tapanuli (Kahar, 1981). 
Secara geografis wilayah Kerinci terletak pada posisi 101008' - 101050' Bujur Timur dan $1041^{\prime}$ - 2026' Lintang Selatan dengan luas kurang lebih 3808.50 km² dan ketinggian tempat antara 450 - $1500 \mathrm{~m}$ dpl. Kabupaten Kerinci berada di sebelah barat Provinsi Jambi yang berjarak $\pm 450 \mathrm{~km}$ dari ibukota propinsi, memiliki batas-batas yaitu sebelah utara dengan Kabupaten Solok Provinsi Sumatera Barat, sebelah selatan dengan Kabupaten Sarko Provinsi Jambi \& Kabupaten Bengkulu Utara Provinsi Bengkulu, sebelah timur dengan Kabupaten Bungo Tebo Provinsi Jambi dan sebelah barat dengan Kabupaten Pesisir Selatan Provinsi Sumatera Barat (BBTNKS, 2011).

Dusun Baru Lempur termasuk Kecamatan Gunung Raya, secara geografis terletak pada posisi 101030' - 101040' Bujur Timur, berjarak kurang lebih 40 km sebelah timur dari kota Sungai Penuh, ibukota Kabupaten Kerinci. Secara administrasi pemerintahan Dusun Baru Lempur adalah pemekaran dari Desa Lempur yang terkenal dengan sebutan Lekuk Lima Puluh Tumbi. Daerah Lekuk 50 Tumbi dikelilingi perbukitan dan diapit dua pegunungan yaitu Gunung Batuah dan Gunung Kunyit. Terdapat banyak danau sebagai sumber mata air yaitu Danau Kaco, Danau Duo, Danau Lingkat, Danau Nyalo dan Danau Kecik. Terletak pada ketinggian 750 m dpl. Masyarakat Dusun Baru Lempur mayoritas suku asli Kerinci (95\%).

Masyarakat Dusun Baru Lempur memiliki sistem sosial yang unik. Sistem sosial adalah suatu pola interaksi social yang terdiri dari komponen-komponen sistem sosial yang teratur dan melembaga (institutionalized). Salah satu karakteristik dari system sosial adalah ia merupakan kumpulan dari beberapa unsur atau komponen yang dapat dijumpai dalam kehidupan bermasyarakat. Komponen-komponen tersebut bersifat non empiris artinya komponen-komponen system dalam masyarakat tidak bisa dilihat dan diamati. Menurut Kartodirjo (1992), suatu sistem sosial dapat dilihat dari peran dan fungsinya yang terdiri dari fungsi adaptasi (A), fungsi pencapaian tujuan (G), fungsi integrasi (I) dan fungsi lattern pattern (L), yang disingkat dengan fungsi AGIL. Sedangkan menurut Talcott Parsons dalam (Narwoko, 2004) terdapat dua hal penting dalam sistem sosial yaitu Sistem sosial harus mampu mendorong warga masyarakat agar berperilaku atau bertindak sesuai dengan harapan dan perannya. Sistem sosial harus menjauhi tuntutan yang aneh-aneh dari para anggotanya agar tidak menimbulkan penyimpangan atau konflik. Oleh karena itu orientasi seseorang melakukan tindakan perlu diketahui yang berarti tindakan tersebut selalu diarahkan untuk mencapai suatu tujuan.

Bahasa masyarakat Kerinci berbeda dengan bahasa daerah lainnya di Sumatera, namun masih berpokok kepada bahasa Melayu Tua (Austronesia) yang dituturkan dengan dialek Kerinci. Perbedaan ini disebabkan oleh letak daerah Kerinci yang terpencil sehingga mempunyai dialek tersendiri. Dialeknya berbeda dengan suku-suku Sumatera lainnya, namun pada umumnya mereka mengerti akan bahasa Melayu atau bahasa Indonesia. Karakteristik dari bahasa Kerinci juga tampak pada dialek yang banyak, berbeda pada setiap daerah.

Berdasarkan hasil penelitian menunjukkan bahwa setiap dusun asli Kerinci memiliki dialek sendiri-sendiri ( \pm 177 dialek sesuai dengan jumlah dusun asli). Di antara faktor yang menyebabkan perbedaan dialek adalah lebih dominannya hubungan genealogis teritorial, sekalipun dusun bertetangga yang hanya dibatasi oleh jalan atau seberangan 
sungai. Perbedaan dialek tidak menyebabkan komunikasi antara dusun terhambat, karena mereka saling mengerti dialek satu sama lain.

Selain dialek yang berbeda pada setiap dusun asli, Kerinci juga memiliki aksara atau huruf sendiri yang disebut dengan aksara incung. Aksara incung telah digunakan orang Kerinci zaman dahulu memiliki bentuk yang khas. Keberadaan aksara incung dapat ditemukan pada dokumen-dokumen lama masyarakat Kerinci. Penulisan tanda bunyi untuk satu aksara incung diantaranya ditemukan 2 atau 3 macam, namun tidak sampai mempengaruhi pembentukan kata atau kalimat dalam sastra incung.

Dalam berkomunikasi dan bertutur, masyarakat Kerinci mengenal istilah empat kali empat (=adat bakato atau bakeramo) yaitu cara berbahasa atau bertutur dengan memperhatikan tata krama dan kedudukan orang yang diajak bicara. Empat kali empat terdiri atas unsur pesan, unsur sifat, unsur perintah dan unsur kerama yang dapat dijelaskan sebagai berikut :

a. Unsur pesan yaitu kata pusaka, kata terletak, kata tersurat dan kata tersirat.

b. Unsur sifat yaitu kata mufakat, kata sepakat, kata bergalau dan kata menghiba.

c. Unsur perintah yaitu kata memutus, kata menyusun, kata nasihat, kata menderas.

d. Unsur kerama yaitu kata mendaki, kata menurun, kata mendatar, kata membayang.

Selain memiliki aksara incung dan keragaman jumlah dialek, masyarakat Kerinci mempunyai kemampuan dalam bertutur dengan menggunakan ungkapan-ungkapan atau idiom-idiom dalam menyampaikan suatu maksud. Ungkapan-ungkapan ini biasa digunakan dalam berkomunikasi antar anggota keluarga atau antar anggota keluarga dalam hubungan bermasyarakat. Ungkapan-ungkapan yang dimiliki oleh masyarakat Kerinci menggambarkan bentuk pengetahuan yang telah mereka miliki terhadap pengelolaan sumber daya alam dan lingkungan. Pengetahuan ini berproses dan diturunkan secara turun temurun dari generasi tua kepada generasi mudanya.

Sedangkan untuk upacara tradisional, masyarakat Dusun Baru Lempur mempunyai banyak upacara dan kesenian tradisional. Semua upacara ini melibatkan banyak orang yang menandakan bahwa suku Kerinci memegang prinsip kesatuan yang kuat, saling membantu dan saling membahu seperti pepatah mereka "kerjo kecik bertabur arai, kerjo gedang bertabur urai". Upacara adat dan kesenian tradisional disetiap wilayah adat atau negeri mengalami sedikit perbedaan tergantung dengan ico pakai masing masing neghoi (negeri//dusun). Ico pakai atau icopake artinya cara untuk melakukan sesuatu yang merupakan adat turun-temurun melalui kesepakatan bersama.

Beberapa bentuk upacara masyarakat Dusun Baru Lempur adalah:

a. Upacara yang berhubungan dengan siklus kehidupan manusia seperti kehamilan, kelahiran, aqiqah, pernikahan dan kematian.

b. Upacara yang berhubungan dengan sistem produksi seperti merendam ramuan kayu, gotong royong membersihkan irigasi, menuai padi, menolak bala, kenduri sudah tuai dan kenduri tengah padang.

c. Upacara yang berhubungan dengan pemerintahan atau kepemimpinan seperti mandi basantan. Uapacara mandi basantan adalah upacara adat yang dilakukan 
pada proses pelantikan depati, pimpinan tertinggi masyarakat adat Kerinci. Calon Depati yang akan dilantik terlebih dahulu diberi minum dengan air santan lemak manis oleh saudara perempuan dan kemudian disiram dengan santan oleh anak datung.

d. Upacara yang berhubungan dengan sistem sosial seperti upacara negak rumah. Upacara negak rumah merupakan kenduri bagi orang yang akan melaksanakan pembangunan rumah dengan mengundang warga kampung, kemudian menegakan tiang utama rumah secara bersama-sama dengan disertakannya wanita yang hamil.

\section{- Amsal, ungkapan dan aturan lama masyarakat kerinci}

Menurut Millenium Ecosystem Assessment (2005), suatu amsal, ungkapan ataupun aturanaturan lama suatu kelompok masyarakat dapat menunjukkan makna jasa lingkungan, yang dikelompokkan menjadi 4 jasa lingkungan yaitu:

1. Jasa penunjang (Supporting services). Diperlukan untuk produksi semua jasa ekosistem lainnya, seperti daur ulang hara, produksi primer dan pembentukan tanah. Layanan ini memungkinkan ekosistem menyediakan layanan seperti pasokan makanan, pengaturan banjir, dan pemurnian air.

2. Jasa penyediaan (Provisioning services). Yaitu produk yang diperoleh dari ekosistem meliputi pangan, bahan baku, sumberdaya genetic, air, mineral, sumber obat dan sumber hias.

3. Jasa budaya (Regulating services). Bermanfaat nonmateri yang diperoleh orang dari ekosistem melalui pengayaan spiritual, perkembangan kognitif, refleksi, rekreasi dan pengalaman estetika.

4. Jasa pengaturan (Cultural services). merupakan manfaat yang diperoleh dari pengaturan proses ekosistem seperti penyerapan karbon, pengaturan iklim, dekomposisi dan detoksifikasi limbah, pemurnian air dan udara, pengendalian hama dan penyakit.

Selanjutnya, berdasarkan studi pustaka dan observasi lapang yang dilakukan pada masyarakat Kerinci berhasil didokumentasikan sebanyak 30 ungkapan tradisional yang terdiri dari amsal, ungkapan dan aturan-aturan lama masyarakat Kerinci sebagaimana Tabel berikut: 
Tabel 1. Dokumentasi Amsal, Ungkapan dan Aturan-aturan Lama Masyarakat Kerinci

\begin{tabular}{|c|c|c|c|c|c|}
\hline No & Bahasa lokal & Bahasa Indonesia & Makna & $\begin{array}{l}\text { Interpretasi } \\
\text { Scientific }\end{array}$ & Jasa Lingkungan \\
\hline 1 & $\begin{array}{l}\text { Adat bumbun menyelaro, adat } \\
\text { padang kepanasan }\end{array}$ & $\begin{array}{l}\text { Adat bumbun menyelara, } \\
\text { adat tanah lapang } \\
\text { kepanasan }\end{array}$ & $\begin{array}{l}\text { Mengambil kesimpulan tanpa } \\
\text { proses sebelumnya. }\end{array}$ & $\begin{array}{l}\text { Perlu penelitian } \\
\text { untuk } \\
\text { mendapatkan } \\
\text { hasil. }\end{array}$ & Cultural service \\
\hline 2 & $\begin{array}{l}\text { Adaik nan ndak lekang dek } \\
\text { panas, dak lapuk dek hujan, } \\
\text { titian teras batanggo batu, jalan } \\
\text { barambah nan diturut, baju } \\
\text { bajait nan dipakai }\end{array}$ & $\begin{array}{l}\text { Adat tidak lekang karena } \\
\text { panas, tidak lapuk karena } \\
\text { hujan }\end{array}$ & $\begin{array}{l}\text { Adat istiadat yang turun } \\
\text { temurun itu baik jika } \\
\text { dilaksanakan agar tidak } \\
\text { menjadi tercela dalam } \\
\text { pandangan orang banyak }\end{array}$ & $\begin{array}{l}\text { Konsisten } \\
\text { terhadap adat } \\
\text { istiadat }\end{array}$ & Cultural service \\
\hline 3 & $\begin{array}{l}\text { Adaik pulei batingkat naik, } \\
\text { adaik manusia batingkat turun }\end{array}$ & $\begin{array}{l}\text { Kebiasaan pulai meningkat } \\
\text { naik, kebiasaan manusia } \\
\text { meningkat turun }\end{array}$ & $\begin{array}{l}\text { Pohon pulai makin tua makin } \\
\text { tinggi batangnya } \\
\text { meninggalkan ruas dan buku. } \\
\text { Begitu pula manusia, setiap } \\
\text { pergantian generasi selalu } \\
\text { meninggalkan sesuatu sebagai } \\
\text { cirinya. }\end{array}$ & $\begin{array}{l}\text { Adanya suksesi } \\
\text { alam }\end{array}$ & $\begin{array}{l}\text { Provisioning } \\
\text { service }\end{array}$ \\
\hline 4 & $\begin{array}{l}\text { Aman ndak ngina' padi njadi, } \\
\text { ina'la padi di kampung bente }\end{array}$ & $\begin{array}{l}\text { Kalau mau melihat padi } \\
\text { menjadi, lihatlah di daerah } \\
\text { yang banyak lumpurnya }\end{array}$ & $\begin{array}{l}\text { Setiap usaha akan berhasil jika } \\
\text { dilaksanakan dengan cara } \\
\text { yang benar serta tempat yang } \\
\text { tepat (cocok) }\end{array}$ & Kesesuaian lahan & Cultural service \\
\hline 5 & Ambil benih campak sarap & $\begin{array}{l}\text { Ambil benih buang } \\
\text { sampah }\end{array}$ & $\begin{array}{l}\text { Ambillah segala sesuatu yang } \\
\text { baik-baik dan bermanfaat saja }\end{array}$ & Sifat selektifitas & Cultural service \\
\hline 6 & $\begin{array}{l}\text { Apo digaduh pengayuh samo di } \\
\text { tangan biduk samo di aek }\end{array}$ & $\begin{array}{l}\text { Duduk sama rendah tegak } \\
\text { sama tinggi }\end{array}$ & $\begin{array}{l}\text { Memiliki hak dan kewajiban } \\
\text { yang sama }\end{array}$ & Keadilan & Regulating service \\
\hline
\end{tabular}




\begin{tabular}{|c|c|c|c|c|c|}
\hline 7 & $\begin{array}{l}\text { Bajalan kincie karno ayiek, } \\
\text { bagoyang dahan karno angin }\end{array}$ & $\begin{array}{l}\text { Berjalan kincir karena air, } \\
\text { bergoyang dahan karena } \\
\text { angin }\end{array}$ & $\begin{array}{l}\text { Terjadinya sesuatu karena } \\
\text { sebab }\end{array}$ & $\begin{array}{l}\text { Hukum sebab } \\
\text { akibat }\end{array}$ & Supporting service \\
\hline 8 & $\begin{array}{l}\text { Bak membelah betung, sebelah } \\
\text { dipijak, sebelah lagi diangkat } \\
\text { tinggi-tinggi }\end{array}$ & $\begin{array}{l}\text { Seperti membelah betung, } \\
\text { sebelah dipijak sebelah lagi } \\
\text { diangkat tinggi-tinggi }\end{array}$ & $\begin{array}{l}\text { Orang yang mau } \\
\text { mengorbankan orang lain } \\
\text { untuk mencapai tujuannya }\end{array}$ & Parasitisme & Cultural service \\
\hline 9 & $\begin{array}{l}\text { Cupak diisei gantei dililit aduek } \\
\text { dituhaak }\end{array}$ & $\begin{array}{l}\text { Cupak diisi gantang } \\
\text { diratakan adat diturut }\end{array}$ & $\begin{array}{l}\text { Kalau berada di suatu daerah } \\
\text { maka kita harus mengikuti } \\
\text { adat kebiasaan daerah } \\
\text { tersebut. }\end{array}$ & $\begin{array}{l}\text { Proses adaptasi } \\
\text { strategi bertahan } \\
\text { hidup. }\end{array}$ & Regulating service \\
\hline 10 & $\begin{array}{l}\text { Elok secanting asal bernih } \\
\text { daripado segantong ampo galou }\end{array}$ & $\begin{array}{l}\text { Elok sedikit asal bernas, } \\
\text { daripada banyak kosong } \\
\text { semua }\end{array}$ & $\begin{array}{l}\text { Biar sedikit asal berkualitas, } \\
\text { daripada banyak tidak } \\
\text { bermutu }\end{array}$ & $\begin{array}{l}\text { Kualitas lebih } \\
\text { penting daripada } \\
\text { kuantitas }\end{array}$ & Cultural service \\
\hline 11 & $\begin{array}{l}\text { Gesuk apai mangka gesuk ayei } \\
\text { luyak }\end{array}$ & $\begin{array}{l}\text { Berlebih api tidak } \\
\text { dimasak, berlebih air } \\
\text { lembek }\end{array}$ & $\begin{array}{l}\text { Pekerjaan yang dilakukan } \\
\text { dengan terburu-buru hasilnya } \\
\text { menjadi tidak sempurna }\end{array}$ & $\begin{array}{l}\text { Bekerja dengan } \\
\text { teliti agar hasil } \\
\text { maksimal }\end{array}$ & Supporting service \\
\hline 12 & $\begin{array}{l}\text { Hanyut dibawa arus ayiek, } \\
\text { dipintas ke muaranya }\end{array}$ & $\begin{array}{l}\text { Hanyut dibawa arus } \\
\text { sungai dipintas ke } \\
\text { muaranya }\end{array}$ & $\begin{array}{l}\text { Mencari sumber masalah harus } \\
\text { ke asalnya }\end{array}$ & Proses alamiah & Regulating service \\
\hline 13 & Idak dijuluk idaknyo luruh & $\begin{array}{l}\text { Tidak dijuluk tidaknya } \\
\text { luruh }\end{array}$ & $\begin{array}{l}\text { Sesuatu yang tidak diusahakan } \\
\text { maka tidak akan didapat }\end{array}$ & Proses alamiah & Regulating service \\
\hline 14 & $\begin{array}{l}\text { Idak pecah ruyung idak kelua } \\
\text { sagu }\end{array}$ & $\begin{array}{l}\text { Tidak pecah ruyung tidak } \\
\text { dia keluar sagu }\end{array}$ & $\begin{array}{l}\text { Segala sesuatu harus } \\
\text { dilakukan dengan kerja keras } \\
\text { untuk mencapai apa yang } \\
\text { dicita-citakan }\end{array}$ & $\begin{array}{l}\text { Kerja keras agar } \\
\text { berhasil }\end{array}$ & Cultural service \\
\hline 15 & $\begin{array}{l}\text { Jatuh di tempat nan rato, anyut } \\
\text { di tempat nan tanang }\end{array}$ & $\begin{array}{l}\text { Jatuh di tempat rata, } \\
\text { hanyut di arus tenang }\end{array}$ & $\begin{array}{l}\text { Terjadinya malapetaka itu } \\
\text { tidak dapat diduga, dapat } \\
\text { datang kapan saja }\end{array}$ & $\begin{array}{l}\text { Selalu hati hati } \\
\text { dan waspada }\end{array}$ & Supporting service \\
\hline
\end{tabular}




\begin{tabular}{|c|c|c|c|c|c|}
\hline 16 & $\begin{array}{l}\text { Ka ayiek cemeti keno, kedarat } \\
\text { duren runtuh, ke dapur lemang } \\
\text { masak }\end{array}$ & $\begin{array}{l}\text { Ke sungai dapat air, ke } \\
\text { darat dapat durian jatuh, } \\
\text { ke dapur dapat lemang } \\
\text { masak }\end{array}$ & $\begin{array}{l}\text { Pemanfaatan sumber daya } \\
\text { alam yang menjadikan hidup } \\
\text { sejahtera dan berkecukupan } \\
\text { (Well being livelihood) }\end{array}$ & $\begin{array}{l}\text { Serasi dengan } \\
\text { alam lingkungan }\end{array}$ & Cultural service \\
\hline 17 & $\begin{array}{l}\text { Kabut nan dalam lah terang, aik } \\
\text { nan keruh lah jernih, lah buli } \\
\text { bebiduk laju, berantau selesai }\end{array}$ & $\begin{array}{l}\text { Kabut yang tebal sudah } \\
\text { terang, air yang keruh } \\
\text { sudah jernih, sudah boleh } \\
\text { berbiduk laju sampai } \\
\text { rantau. }\end{array}$ & $\begin{array}{l}\text { Masalah yang sudah jernih } \\
\text { duduk perkaranya (masalah } \\
\text { sudah menemukan solusi) }\end{array}$ & $\begin{array}{l}\text { Ada solusi dari } \\
\text { suatu masalah }\end{array}$ & Regulating service \\
\hline 18 & $\begin{array}{l}\text { Kalau dak tembilang patah } \\
\text { tanaman tekalik }\end{array}$ & $\begin{array}{l}\text { Kalau tembilang patah } \\
\text { tanaman tercabut }\end{array}$ & $\begin{array}{l}\text { Sikap tegas dan berani dalam } \\
\text { menyelesaikan permasalahan } \\
\text { yang tidak dapat diselesaikan } \\
\text { sendiri }\end{array}$ & $\begin{array}{l}\text { Harus bersikap } \\
\text { berani dan tegas }\end{array}$ & $\begin{array}{l}\text { Provisioning } \\
\text { service }\end{array}$ \\
\hline 19 & $\begin{array}{l}\text { Kalau pandai membeli sirih. } \\
\text { Jangan dibeli sirih udang. Kalau } \\
\text { pandai meniti buih, selamat } \\
\text { badan hingga seberang. }\end{array}$ & $\begin{array}{l}\text { Kalau pandai membeli } \\
\text { sirih Jangan dibeli sirih } \\
\text { udang. Kalau pandai } \\
\text { meniti buih, selamat badan } \\
\text { hingga seberang }\end{array}$ & $\begin{array}{l}\text { Pandai-pandai dalam } \\
\text { menjalani kehidupan hingga } \\
\text { selamat sampai tujuan }\end{array}$ & Hukum alamiah & Supporting service \\
\hline 20 & $\begin{array}{l}\text { Kalo samo tinggi kayau di rimbo } \\
\text { mano pulo tampaik angin lalau }\end{array}$ & $\begin{array}{l}\text { Kalau sama tinggi pohon } \\
\text { di hutan, dimana pula } \\
\text { tempat angin lalu }\end{array}$ & $\begin{array}{l}\text { Tinggi rendah kehidupan tidak } \\
\text { saling mempersulit, melainkan } \\
\text { saling mendatangkan manfaat } \\
\text { kepada banyak orang }\end{array}$ & Simbiosis & Supporting service \\
\hline 21 & $\begin{array}{l}\text { Keruh ayiek diiliie prikso di } \\
\text { ulunyo, senak aik di ulu prikso } \\
\text { ka muaro }\end{array}$ & $\begin{array}{l}\text { Keruh air di hilir, periksa } \\
\text { ke hulunya, dalam air di } \\
\text { hulu periksa ke muaranya }\end{array}$ & $\begin{array}{l}\text { Usut semua kejadian dengan } \\
\text { cermat sambil meneliti tempat } \\
\text { dan sebab musabab terjadinya } \\
\text { peristiwa tersebut. }\end{array}$ & $\begin{array}{l}\text { Penurunan } \\
\text { genetik, proses } \\
\text { alami }\end{array}$ & $\begin{array}{l}\text { Provisioning } \\
\text { service }\end{array}$ \\
\hline 22 & $\begin{array}{l}\text { Laksano kayu di dalam utan, } \\
\text { patah tumbuh ilang beganti }\end{array}$ & $\begin{array}{l}\text { Laksana kayu di dalam } \\
\text { hutan, patah tumbuh } \\
\text { hilang berganti }\end{array}$ & $\begin{array}{l}\text { Semua pihak diharapkan } \\
\text { menyiapkan dan bertanggung } \\
\text { jawab terhadap terjadinya } \\
\text { proses tersebut }\end{array}$ & $\begin{array}{l}\text { Gambaran } \\
\text { terjadinya } \\
\text { regenerasi }\end{array}$ & Cultural service \\
\hline
\end{tabular}




\begin{tabular}{|c|c|c|c|c|c|}
\hline 23 & $\begin{array}{l}\text { Mano tambilang taentak, disitu } \\
\text { tanaman tumbuh, mano bumi } \\
\text { dipijak disitu langik dijunjuang }\end{array}$ & $\begin{array}{l}\text { Dimana tembilang } \\
\text { terhentak, disitu tanaman } \\
\text { tumbuh, dimana bumi } \\
\text { dipijak disitu langit } \\
\text { dijunjung }\end{array}$ & $\begin{array}{l}\text { Harus menyesuaikan dan } \\
\text { membuat strategi dengan } \\
\text { lingkungan sekitar }\end{array}$ & $\begin{array}{l}\text { Adaptasi dan } \\
\text { strategi }\end{array}$ & Supporting service \\
\hline 24 & $\begin{array}{l}\text { Mati kuman sama dicacah, mati } \\
\text { gajah sama dilapah }\end{array}$ & $\begin{array}{l}\text { Mati kuman sama dicecah, } \\
\text { mati gajah sama dilapah }\end{array}$ & $\begin{array}{l}\text { Pembagian yang rata antara } \\
\text { satu dengan yang lain }\end{array}$ & Keadilan & $\begin{array}{l}\text { Provisioning } \\
\text { service }\end{array}$ \\
\hline 25 & $\begin{array}{l}\text { Simbai ekornya, tajam tajinya, } \\
\text { nyaring kokoknya }\end{array}$ & $\begin{array}{l}\text { Simbai ekornya, tajam } \\
\text { tajinya, nyaring kokoknya }\end{array}$ & $\begin{array}{l}\text { Pemimpin yang bijaksana } \\
\text { menjadi panutan masyarakat. }\end{array}$ & $\begin{array}{l}\text { Syarat seorang } \\
\text { pemimpin }\end{array}$ & Cultural service \\
\hline 26 & $\begin{array}{l}\text { Siso angin nan memuput, siso } \\
\text { gelombang nan mengempoh }\end{array}$ & $\begin{array}{l}\text { Sisa angin yang memuput, } \\
\text { sisa gelombang yang } \\
\text { menghempas }\end{array}$ & $\begin{array}{l}\text { Sesuatu kejadian yang } \\
\text { meninggalkan bekas }\end{array}$ & Proses alamiah & Regulating service \\
\hline 27 & $\begin{array}{l}\text { Tebing runtuh tepian beranjak, } \\
\text { tanjung putus teluk beralih }\end{array}$ & $\begin{array}{l}\text { Tebing runtuh tepian } \\
\text { beranjak, tanjung putus } \\
\text { teluk beralih }\end{array}$ & $\begin{array}{l}\text { Suatu kejadian akan membawa } \\
\text { perubahan, manusia harus siap } \\
\text { menerimanya. }\end{array}$ & $\begin{array}{l}\text { Dinamika } \\
\text { kehidupan }\end{array}$ & $\begin{array}{l}\text { Provisioning } \\
\text { service }\end{array}$ \\
\hline 28 & $\begin{array}{l}\text { Tuah umah buuha tuah nagrei } \\
\text { batunggau }\end{array}$ & $\begin{array}{l}\text { Tuah rumah berorang, } \\
\text { tuah negeri berpenghulu }\end{array}$ & $\begin{array}{l}\text { Rumah akan terawat kalau } \\
\text { ditempati, negeri pun akan } \\
\text { hidup dan ramai jika diurus } \\
\text { dengan baik oleh rakyatnya }\end{array}$ & $\begin{array}{l}\text { Suatu negeri } \\
\text { dikatakan indah } \\
\text { bila ada } \\
\text { penghuninya }\end{array}$ & Regulating service \\
\hline 29 & $\begin{array}{l}\text { Urang kayo bertabur urai, } \\
\text { urang mulio bertabur budi }\end{array}$ & $\begin{array}{l}\text { Orang kaya bertabur urai, } \\
\text { orang mulia bertabur budi }\end{array}$ & $\begin{array}{l}\text { Orang kaya rajin bersedekah, } \\
\text { orang mulia itu banyak budi }\end{array}$ & $\begin{array}{l}\text { Berbuat sesuai } \\
\text { dengan } \\
\text { kemampuan }\end{array}$ & Regulating service \\
\hline 30 & $\begin{array}{l}\text { Perahu lentik dak do bepanggar, } \\
\text { kurang lajunyo. Awak cerdik } \\
\text { dak ndak belajar, kurang } \\
\text { tahunyo }\end{array}$ & $\begin{array}{l}\text { Sampan tidak punya } \\
\text { pagar, kecepatannya akan } \\
\text { lambat. Walaupun cerdik } \\
\text { tapi tidak belajar, kurang } \\
\text { pengetahuannya }\end{array}$ & $\begin{array}{l}\text { Untuk mencapai sesuatu harus } \\
\text { mempunyai sarana prasarana } \\
\text { yang cukup dan lengkap }\end{array}$ & $\begin{array}{l}\text { Diperlukan } \\
\text { prasyarat untuk } \\
\text { mencapai suatu } \\
\text { tujuan }\end{array}$ & Supporting service \\
\hline
\end{tabular}

Keterangan: Cultural service 10, supporting service 7, regulating service 8 , provisioning service 5 
Tabel hasil diatas menunjukkan bahwa masyarakat Kerinci memiliki kemampuan dalam bertutur, dengan menggunakan ungkapan-ungkapan baik berupa peribahasa, pepatah, petitih dan aturan-aturan lokal. Beberapa ungkapan itu antara lain : (1) "Adaik nan ndak lekang dek panas, dak lapuk dek hujan, titian teras batanggo batu, jalan barambah nan diturut, baju bajait nan dipakai", (2) "mano tambilang taentak, disitu tanaman tumbuh, mano bumi dipijak disitu langik dijunjuang", (3) "kalo samo tinggi kayau di rimbo mano pulo tampaik angin lalau", (4) "simbai ekornya, tajam tajinya, nyaring kokoknya" dan (5) "adaik pulei batingkat naik, adaik manusia batingkat turun".

Dari hasil penelitian kepada narasumber di Dusun Baru Lempur dapat diperoleh sebanyak 30 ungkapan masyarakat Kerinci yang bersifat lisan, diwariskan secara turun temurun kepada generasi berikutnya. Ungkapan ini terdiri dari amsal, pepatah dan aturan-aturan lama masyarakat Kerinci, yang mempunyai makna jasa lingkungan. Berdasarkan analisis data, diperoleh sebanyak 10 ungkapan dengan makna cultural service, 7 supporting service, 8 regulating service dan 5 provisioning service.

Ungkapan dengan makna cultural service antara lain: Adat bumbun menyelaro, adat padang kepanasan; Adaik nan ndak lekang dek panas, dak lapuk dek hujan, titian teras batanggo batu, jalan barambah nan diturut, baju bajait nan dipakai; Aman ndak ngina 'padi njadi, ina'la padi di kampung bente dan Ambil benih campak sarap. Adat bumbun menyelaro, adat padang kepanasan memiliki arti bahwa seseorang dalam mengambil kesimpulan tanpa proses sebelumnya sehingga tentu kesimpulan yang diambil akan bersifat lemah dan tidak valid. Ini termasuk makna jasa budaya (cultural service) karena menunjukkan sifat manusia pada umumnya yang suka mengambil kesimpulan tanpa pikir panjang terlebih dahulu, yang akhirnya akan membawa kepada penyesalan. Sedangkan ungkapan "Adaik nan ndak lekang dek panas, dak lapuk dek hujan, titian teras batanggo batu, jalan barambah nan diturut, baju bajait nan dipakai" yang bermakna adat istiadat yang turun temurun itu baik jika dilaksanakan agar tidak menjadi tercela dalam pandangan orang banyak. Ungkapan ini menyatakan bahwa masyarakat Kerinci akan tetap mempertahankan adat istiadat yang mereka miliki. Ungkapan ini telah menjadi suatu kesepakatan masyarakat Kerinci sehingga dapat dikategorikan sebagai cultural dalam jasa ekosistem mereka. Adapun ungkapan Aman ndak ngina 'padi njadi, ina'la padi di kampung bente memiliki makna bahwa setiap usaha akan berhasil jika dilaksanakan dengan cara yang benar serta tempat yang tepat (cocok).

Ungkapan supporting berkaitan dengan kehidupan sehari-hari dalam menata hidup untuk kesejahteraan hidup mereka. Hasil analisis data menunjukkan bahwa ungkapan yang mempunyai makna supporting service ada 7 ungkapan, antara lain bajalan kincie karno ayiek, bagoyang dahan karno angina, Jatuh di tempat rata, hanyut di arus tenang, Perahu lentik dak do bepanggar, kurang lajunyo. Awak cerdik dak ndak belajar, kurang tahunyo, Kalau pandai membeli sirih, jangan dibeli sirih udang. Kalau pandai meniti buih, selamat badan hingga seberang dan Mano tambilang taentak, disitu tanaman tumbuh, mano bumi dipijak disitu langik dijunjuang Jatuh di tempat rata, hanyut di arus tenang memiliki arti bahwa terjadinya malapetaka itu tidak dapat diduga, dapat datang kapan saja. Hal ini menunjukkan sikap kehati-hatian, walau di tempat yang baik juga tetap menjaga diri, karena namanya 
musibah dan kejadian buruk dapat terjadi dimana dan kapan saja. Kalau pandai membeli sirih, jangan dibeli sirih udang. Kalau pandai meniti buih, selamat badan hingga seberang.

Bermakna agar jadi orang itu harus pandai-pandai dalam menjalani kehidupan hingga selamat sampai tujuan. Masyarakat Kerinci memahami bahwa dalam kehidupan itu harus ada proses adaptasi dan strategi yang dilakukan, sehingga menjadi betah dan dapat bertahan hidup dimanapun berada, sebagaimana ungkapan "mano tambilang taentak, disitu tanaman tumbuh, mano bumi dipijak disitu langik dijunjuang" yang berarti dimana tembilang terhentak, disitu tanaman tumbuh, dimana bumi dipijak disitu langit dijunjung. Dalam proses adaptasi terhadap lingkungan dapat dilihat dari kemampuan mereka mengolah sumber daya lahan berdasarkan topografi dan kemiringan lahan. Wilayah Kerinci yang berupa hamparan datar yang dikelilingi oleh perbukitan dan pegunungan di sekelilingnya mampu mereka olah dengan strategi adaptasi yang baik sebagaimana nampak pada gambar 1 berikut:

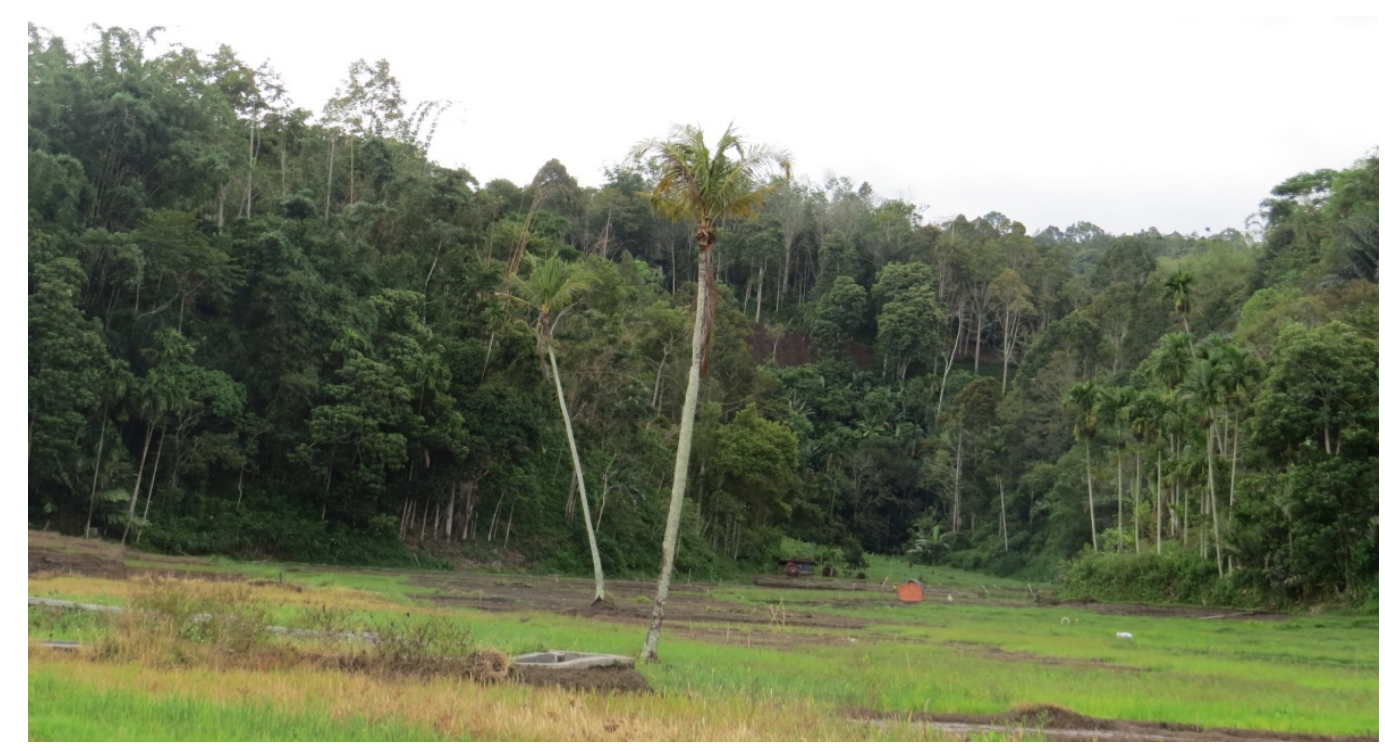

Gambar 1: Pengolahan lahan masyarakat Kerinci menurut ketinggian tempat, bentuk strategi adaptasi terhadap ketinggian tempat

Ungkapan ini juga telah menjadi supporting bagi masyarakat Kerinci sejak lama, terutama bagi mereka yang merantau. Masyarakat Kerinci dikenal sebagai masyarakat perantau, mereka keluar dari kampung untuk mengembangkan diri dan mencari ilmu pengetahuan. Ungkapan ini dipegang dan diamalkan oleh masyarakat Kerinci, sehingga mereka bisa betah dan mampu bertahan walau jauh dari kampung.

Selanjutnya, ungkapan "kalo samo tinggi kayau di rimbo mano pulo tampaik angin lalau" yang berarti tinggi rendah kehidupan tidak saling mempersulit, melainkan saling mendatangkan manfaat kepada banyak orang. Ungkapan ini menyatakan bahwa masyarakat Kerinci sudah memiliki pengetahuan bahwa di alam ini ada simbiosis kehidupan. Adanya saling ketergantungan antara satu makhluk hidup dengan makhluk hidup lain di sekitarnya. Ungkapan ini menjadi provisioning bagi mereka dalam 
melakukan aktivitas keseharian. Hal ini antara lain dapat dilihat dari harmonisasi kehidupan Masyarakat Kerinci dengan sumberdaya alam yang ada di sekitar mereka, sebagaimana dilihatkan pada gambar 2 berikut:

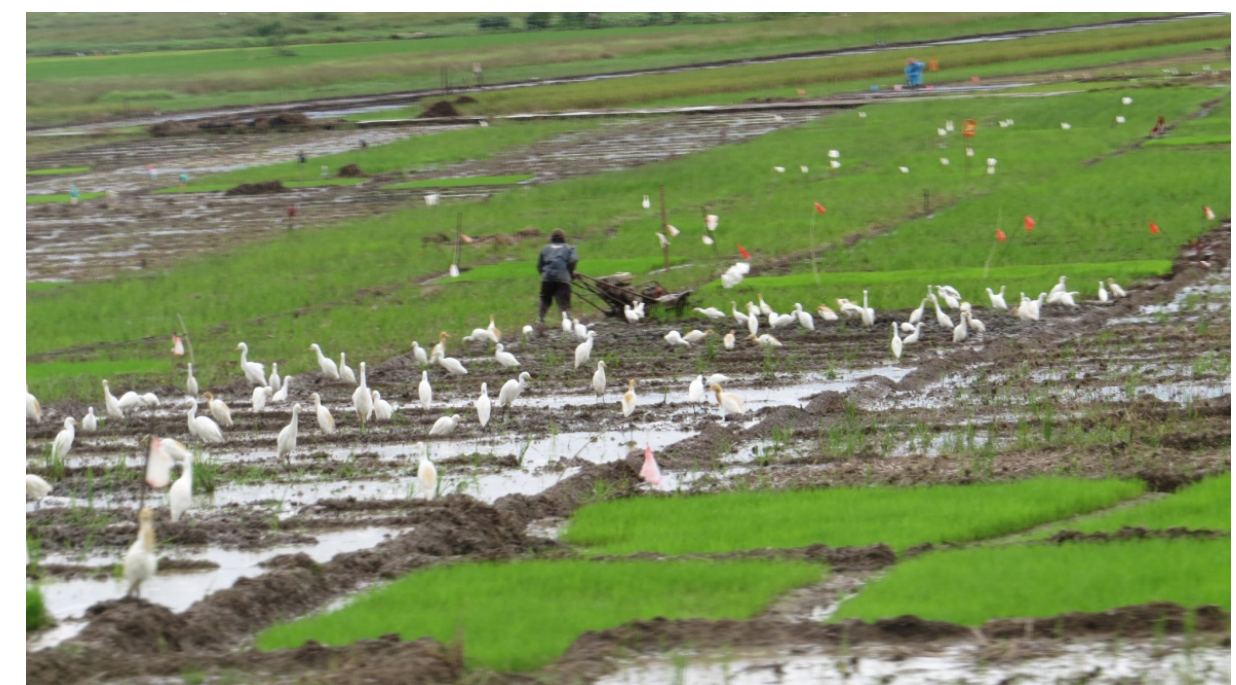

Gambar 2: Simbiosis kehidupan petani Kerinci dengan spesies burung kuntul (Bubulcus sp) dari famili Ardeidae

Sedangkan ungkapan "simbai ekornya, tajam tajinya, nyaring kokoknya" adalah ungkapan terhadap seorang pemimpin. Pemimpin itu harus memiliki ciri-ciri memiliki kemampuan baik secara materi maupun non materi (pendidikan), harus berani dan pintar bicara, sehingga disegani oleh para anggota yang dipimpinnya. Ungkapan ini merupakan aturan lokal (cultural) bagi masyarakat Kerinci dalam memilih depati (pemimpin adat mereka).

Ungkapan "adaik pulei batingkat naik, adaik manusia batingkat turun" yang berarti kebiasaan pulai meningkat naik, kebiasaan manusia meningkat turun dimaknai terhadap adanya proses regenerasi. Pohon pulai makin tua makin tinggi batangnya meninggalkan ruas dan buku, begitu pula manusia, setiap pergantian generasi selalu meninggalkan sesuatu sebagai cirinya. Ungkapan ini menjadi provisioning bagi masyarakat Kerinci dan telah berlangsung sejak lama.

\section{Penutup}

Hasil penelitian menunjukkan bahwa Masyarakat Kerinci sudah memiliki bentuk pengetahuan yang dapat dilihat dari ungkapan-ungkapan seperti peribahasa, petatah petitih dan aturan-aturan lokal yang telah lama mereka sepakati dan gunakan.Terdapat sebanyak 30 ungkapan lama masyakarat Kerinci yang terdiri dari pepatah, peribahasa dan ungkapan lama. Ungkapan-ungkapan ini mengungkapkan kebenaran, kebijaksanaan, atau pelajaran tentang alam dan moral yang diperoleh berdasarkan akal sehat dan pengalaman-pengalaman praktis anggota masyarakatnya.

Ungkapan-ungkapan ini menunjukkan bahwa masyarakat tradisional memiliki pengetahuan yang mereka peroleh dari alam dan ekosistem dimana mereka tinggal. 
Mereka mampu mengungkapkan suatu hal atau suatu kejadian dari fenomena alam yang terjadi atau tanda-tanda alam yang muncul. Terdapat banyak pesan moral yang masih berlaku hingga zaman kini yang dapat dikelompokkan ke dalam 4 jasa ekosistem yang terdiri dari cultural service, regulating service, supporting service dan provisioning service.

Acknowledgments

Kami ucapkan terima kasih kepada masyarakat Kerinci khususnya tokoh dan masyarakat Desa Lempur yang telah membantu informasi proverb dan old sayingsnya, serta ICRAF yang telah memberikan dana guna penelitian ini

Conflicts of interest

Author declares no conflict of interest.

Referensi

Anderson, E. N. (2011). Ethnobiology: Overview of a Growing Field. In Ethnobiology (pp. 1-14). John Wiley and Sons. https://doi.org/10.1002/9781118015872.ch1

BBTNKS. (2011). Taman Nasional Kerinci Seblat (West Sumatra, Indonesia) - Review. https://www.tripadvisor.co.id/Attraction_Review-g2301784-d6607681-ReviewsKerinci_Seblat_National_Park-West_Sumatra_Sumatra.html

Galacgac, E. S., \& Balisacan, C. M. (2009). Traditional weather forecasting for sustainable agroforestry practices in Ilocos Norte Province, Philippines. Forest Ecology and Management, 257(10), 2044-2053. https://doi.org/10.1016/j.foreco.2009.01.002

Helida, A. (2016). Integrasi Etnobiologi Masyarakat Kerinci Dalam Konservasi Sumberdaya Alam Hayati dan Ekosistemnya. http:/ / repository.ipb.ac.id/handle/123456789/82379

Irawan, P. (2006). Penelitian Kualitatif Dan Kuantitatif Untuk Ilmu-ilmu Sosial. DIA Fisip UI.

Kahar. (1981). (PDF) Bab-11R-SEJARAH KEB-ALAM KERINCI-01 | RIZAL IKHSAN Academia.edu.

https://www.academia.edu/6568242/Bab_11R_SEJARAH_KEB_ALAM_KERIN CI_01

Kartodirjo Sartono. (1992). Pendekatan ilmu sosial dalam metodologi sejarah -. Http:/ / Repository.Um-Palembang.Ac.Id/Id/Eprint/9844. http://repository.umpalembang.ac.id/id/eprint/9844/

Millenium Ecosystem Assessment. (2005). Ecosystems and Human Weel-Being; Synthesis. Island Press.

Narwoko JD, S. B. (2004). Sosiologi Teks Pengantar dan Terapan. Kencana Prenada Media Group.

Neuman. (2006). Social Research Methods Qualitative and Quantitative Approaches. - Bing images. University of Wisconsin at Whitewater. https:// www.bing.com/images/search?view=detailV2\&ccid=V\%2FEaAlN3\&id= C4F4602412914803F72CF3DCE56F8357EACB5625\&thid=OIP.V_EaAIN3aLQPUm a6KaWMxQHaJn\&mediaurl=https $\% 3 \mathrm{~A} \% 2 \mathrm{~F} \% 2 \mathrm{Fwww}$.pearsonhighered.com $\% 2 \mathrm{Fa}$ ssets \%2Fbigcovers\%2F0\%2F2\%2F0\%2F5\%2F0205457932.jpg\&exph=648\&

Ronald Mason. (2020). Archaeology and Native North American Oral Traditions on JSTOR. Cambridge University Press. https://doi.org/10.2307/2694058

United Nation. (2014). Indigenous Peoples in the Asia-Pacific region. 
https://asiapacific.unfpa.org/en/news/rights-indigenous-peoples-must-beprotected-and-respected

Vansina. (1985). Oral Tradition: A Study in Historical Methodology | Jan Vansina | download. https:/ / b-ok.asia/book/5223093/5b07df?regionChanged=\&redirect $=174380843$

Zakaria. (2012). SEJARAH ADAT SAKTI ALAM KERINCI: Sejarah Awal Mulanya Kerinci (Kabupaten Kerinci-Jambi). Saktialam.Blogspot.Com. https:// saktialam.blogspot.com/2015/10/sejarah-awal-mulanya-kerincikabupaten.html

Zhang, L., Chai, Z., Zhang, Y., Geng, Y., \& Wang, Y. (2016). Ethnobotanical study of traditional edible plants used by the Naxi people during droughts. https:// doi.org/10.1186/s13002-016-0113-z 